\title{
Spoerhase, Carlos, Werle, Dirk, Wild, Markus, Unsicheres Wissen. Skeptizismus und Wahrscheinlichkeit 1550-1850
}

\section{Claire Gantet}

\section{OpenEdition}

\section{Journals}

Édition électronique

URL : http://journals.openedition.org/ifha/2135

DOI : 10.4000/ifha.2135

ISSN : 2198-8943

Éditeur

IFRA - Institut franco-allemand (sciences historiques et sociales)

Référence électronique

Claire Gantet, «Spoerhase, Carlos, Werle, Dirk, Wild, Markus, Unsicheres Wissen. Skeptizismus und Wahrscheinlichkeit 1550-1850", Revue de l'IFHA [En ligne], Date de recension, mis en ligne le 01 janvier 2010, consulté le 22 septembre 2020. URL : http://journals.openedition.org/ifha/2135 ; DOI : https:// doi.org/10.4000/ifha.2135

Ce document a été généré automatiquement le 22 septembre 2020.

(C)IFHA 


\title{
Spoerhase, Carlos, Werle, Dirk, Wild, Markus, Unsicheres Wissen. Skeptizismus und Wahrscheinlichkeit 1550-1850
}

\author{
Claire Gantet
}

Issu d'un colloque tenu en avril 2007, ce recueil interroge les enjeux épistémologiques et méthodologiques des formes de savoir incertain chez les lettrés entre 1550 et 1850. Pour ce faire, il rapproche deux courants différents de l'enquête en histoire des savoirs : la recherche sur le probabilisme et celle sur le scepticisme. Le recueil se divise en deux parties, consacrées au scepticisme et à la probabilité, vue comme l'une des approches constructives du scepticisme. Il élargit par là l'interrogation à des domaines peu, voire pas étudiés par l'histoire de la philosophie et des idées : la théologie (S.K. Knebel, R. Schüßler et S. Richter), la médecine (I. Maclean), les mathématiques (C. Menke), la philosophie (O.R. Scholz, D. Perler, M. Wild), la théorie de la science (C. Wilson), l'herméneutique (L. Danneberg, A. Horstmann et C. Spoerhase), l'historiographie (A.U. Sommer et M. Völkel), les belles lettres (M. Bergengruen, V. Olejniczak Lobsien et D. Werle). La première partie souligne et illustre la nécessité de différencier la notion de scepticisme, à l'encontre du livre fondateur de Richard Popkin, qui rassemblait toute la philosophie de l'époque moderne sous le thème d'une crise pyrrhonienne, provoquée par les troubles religieux et la redécouverte des écrits de Sextus Empiricus. Si certains des thèmes abordés ne sont pas très neufs (ainsi les liens intellectuels entre le débat sur la sorcellerie et l'hypothèse cartésienne du malin génie, ou l'influence pyrrhonienne de Montaigne), cette partie explore aussi de façon très novatrice la complexité des recours - à l'épicurisme, à l'histoire universelle, etc. - et des idéaux - ainsi, par exemple, une science naturelle qui puisse aller au-delà des entités matérielles - suscités par la mise en doute. La seconde partie sonde d'un point de vue historiographique, méthodologique, philologique et littéraire les conceptions de la probabilité. Elle nuance là aussi fortement une thèse reçue : celle d'une discontinuité radicale entre l'époque moderne et les périodes précédentes, formulée dans l'ouvrage standard sur " 
l'émergence de la probabilité » publié par Ian Hacking en 1975. L'étude d'approches quantitatives et qualitatives de la probabilité permet de jeter un regard neuf sur l'épistémologie du témoignage interrogé d'après des objets très divers : la question de la croyance aux miracles, celle de la connaissance historique, celle de la logique et celle, plus éthique, de la certitude.

2 Au total, cet ouvrage, en mettant en lumière la pluralité des interrogations sur les manques et les pertes de savoir, contribue à enrichir la notion de révolution scientifique, à l'élargir dans le temps et à des domaines tels que la philologie, l'historiographie et la théologie. À ce titre, il est un jalon essentiel dans l'histoire et l'historiographie des sciences. On regrette juste que l'histoire du droit n'ait pas été prise en compte et que le livre ne propose pas d'analyses de cas empiriques ou de polémiques concrètes, au-delà des enjeux intellectuels, théoriques et méthodologiques.

Claire Gantet (Université Paris I - Freie Universität Berlin) 